\title{
SOME PROBLEMS IN THE HISTO- PATHOLOGY OF GENERAL PARALYSIS OF THE INSANE
}

By A. J. GALBRAITH, M.D., D.P.M.

(From the Malaria Treatment Centre, Horton Hospital, Epsom.)

\section{INTRODUCTION}

The problems and peculiarities of the histological changes associated with general paralysis of the insane may be considered from two distinct viewpoints. Either these changes may be described with meticulous regard for individual detail, or they may be surveyed in a wider sense, identifying only the broadest types of pathological reactions, but paying closer attention to the etiological aspects of these reactions and their relationship to other neurohistological syndromes. It is largely the second course which will be adopted in this paper, not only because the study of the broader fundamental principles is likely to arouse more interest, but because such an approach is frequently the more instructive.

\section{General Findings}

It would seem advisable before entering upon the discussion of the more obscure lesions to review briefly those changes which constitute the "text-book" picture of general paralysis. In the untreated case, at any rate, one expects to find a degree of cortical atrophy of the cerebral hemispheres. This atrophy is typically confined to approximately the anterior two-thirds of the cortex, tending to be most marked in the frontal poles and gradually diminishing in the more posterior regions. The occipital lobe itself is rarely atrophic and the area striata appears to be particularly immune from the process. Some degrees of atrophy merely give the appearance of slightly widened sulci, but in the more severe forms of the disease the hemispheres are visibly shrunken. Cover- 


\section{BRITISH JOURNAL OF VENEREAL DISEASES}

ing the affected areas of the cortex and sometimes extending over the occipital lobes, the pia-arachnoid may show macroscopical changes in the form of odema, injection, or slight opaque thickening. In contradistinction to the distribution of the cortical atrophy in general paralysis, the areas affected in cerebral arteriosclerosis, in carbon monoxide poisoning, and in senile

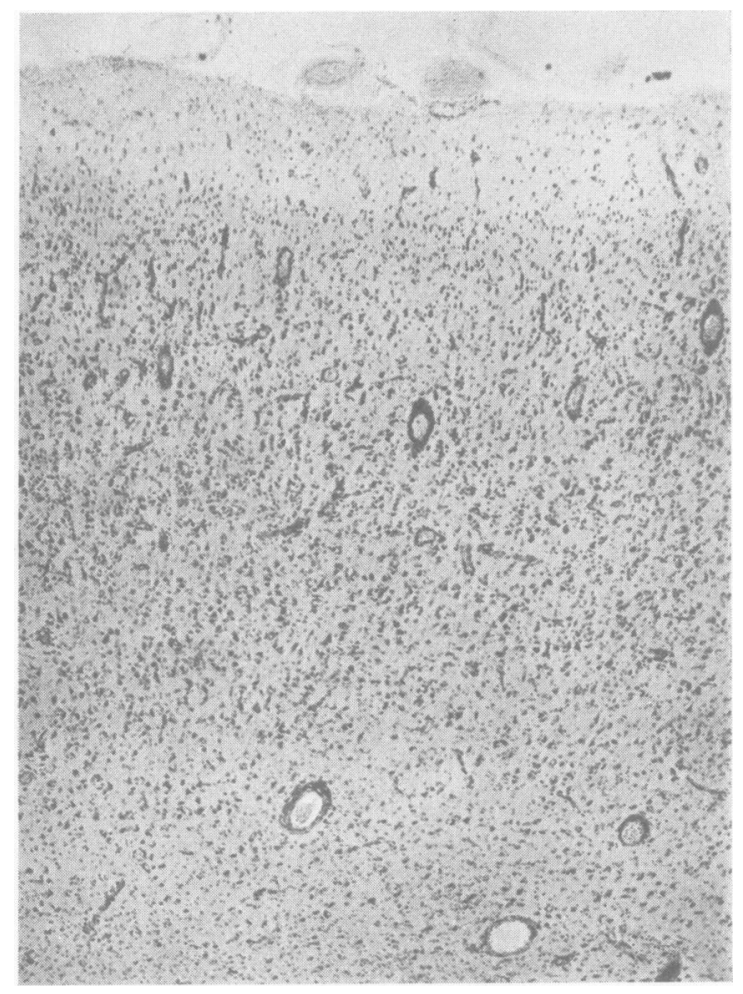

FIG. I.-Cortex in early stage of G.P.I., showing marked inflammatory reaction, but with only slight disturbance of cytoarchitectonic structure.

dementia, are chiefly in the posterior parts of the cortex. Histological examination of the affected cortex in general paralysis reveals a variable amount of disorganisation of the ganglion cells. In an early or mild case the degree of nerve cell involvement may be represented by a slight diffuse loss of the ganglion cells and a somewhat irregular distribution and arrangement of the surviving elements (Fig. I). In later stages there is a progressive degeneration of nerve cells, both diffusely and with focal accentuations 


\section{GENERAL PARALYSIS OF THE INSANE}

of the process, the latter giving rise to an appearance which has been described as "dropping out" of ganglion cells, and is usually confined to the third and fifth layers of the cortex. The terminal stage of the disease is reached when, in a much atrophied grey matter, there remain only a few degenerating nerve cells (Fig. 2). The inflammatory changes in the process are represented by the round celled

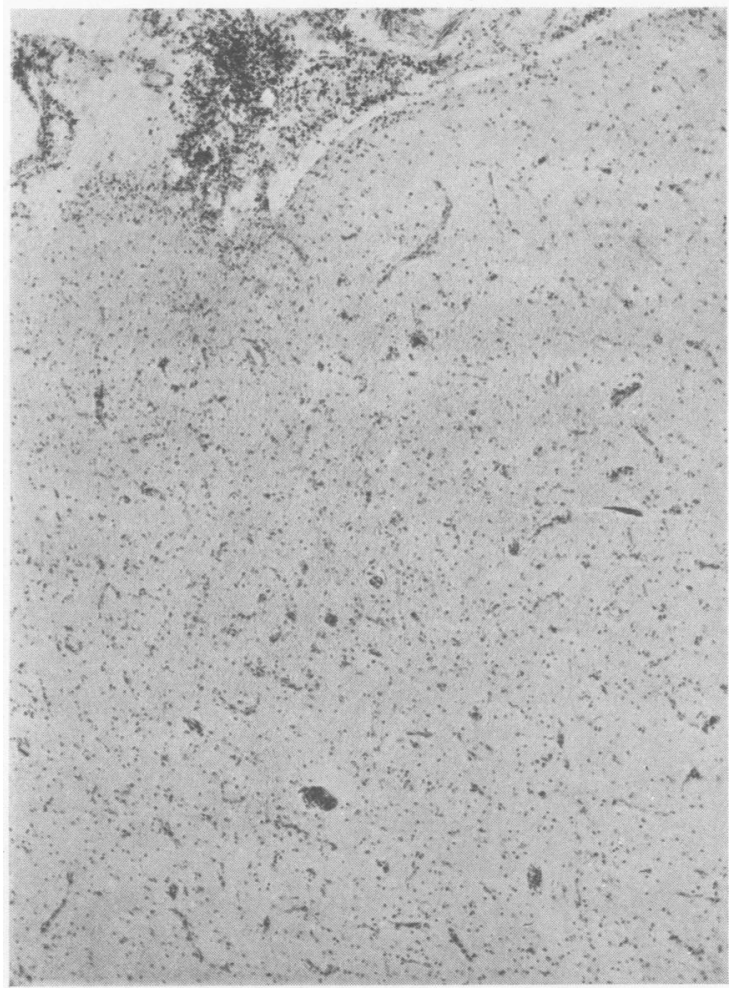

FIG. 2.-Cortex in late stage of untreated G.P.I., showing almost complete destruction of ganglion cells, the nuclei of glial cells much in evidence. Signs of inflammation present.

infiltration of the small cortical vessels and leptomeninges. The infiltrating cells consist of lymphocytes and plasma cells, the latter being distinguished by the slightly red appearance of the protoplasm which is relatively abundant, and the "cartwheel " distribution of the nuclear chromatin. The plasma cell infiltration is much more specific for general paralysis, as it is for syphilitic processes in general, than is a lymphocytic reaction, although 


\section{BRITISH JOURNAL OF VENEREAL DISEASES}

both forms are usually present. Around the vessels, the plasma cells are frequently closely applied to the walls in a "paving stone" fashion, but in the leptomeninges they tend to be more rounded in form. Infiltrations of the vessels of the white matter are also found, but are not so characteristic. Even in the earlier stages of the disease, where the cytoarchitectonic. structure of the cortex is relatively intact, the perivascular infiltration may be quite pronounced, and death at this stage must presumably be due solely to the toxic results of the spirochætal invasion.

As in any other infective process, a reaction of the connective tissue elements enters into the histological picture, and consists in this instance of a proliferation of the sessile glia alone, and does not incur the mobilisation of the glial "scavenger" cells, or of the mesenchymal elements. At the surface of the cortex the layer of glial fibres becomes greatly accentuated, forming the so-called subpial "felting" of fibres. The macroglia proliferate and numerous astrocytes may be demonstrated throughout the cortex, but chiefly in the deeper layers adjacent to the white matter. Lastly, the microglial reaction results in the formation of Hortega " rod " cells, whose abundance and distribution constitute one of the most characteristic histological changes in general paralysis. The " rod " cells are typically arranged in rows vertical to the surface of the cortex, but occasionally accumulations of these cells are observed around the blood-vessels. In no other pathological condition occurring in man is this characteristic microglial proliferation to be found, but a very similar appearance has been noted in the disease affecting domestic fowls, known as " spontaneous encephalitis." Rod cells are also found in trypanosomiasis and occasionally in atypical forms of epidemic encephalitis.

The demonstration of the Spirochata pallida in the brain is, of course, pathognomonic for general paralysis, and if adequate examination of the material is made the organism may be demonstrated in about 60 per cent. of untreated cases. The distribution of the spirochæte is usually diffuse throughout the cortical grey matter, with frequent accumulations around the blood-vessels, and occasionally focal masses of the organism have been observed. Jahnel has drawn attention to the fact that spirochætes are apt to be especially abundant in cases 


\section{GENERAL PARALYSIS OF THE INSANE}

dying during convulsive attacks, but the clinical and pathological relationships of these focal masses of spirochætes are still uncertain.

Apart from the cerebral cortex, the typical pathological process in general paralysis may affect other regions of the central nervous system. In the Basal Ganglia the Corpus Striatum is frequently the site of infiltrations and cell degeneration, whereas the Globus Pallidus is usually spared. Again it is of interest to note that Globus Pallidus is usually severely involved in poisoning with carbon monoxide. Damage to the Corpus Striatum no doubt explains in many instances the occurrence of the typical facies and tremors of general paralysis. The involvement of the hypothalamic regions is also more constant than is generally recognised, and the analysis of lesions in this sphere should prove most profitable in the physiological study of the Hypothalamus, in addition to providing a rational basis for clinical manifestations such as the progressive inanition which is not infrequent in general paralysis. Perivascular infiltration and nerve cell degeneration may be found in practically any region of the brain stem, cerebellum and spinal cord in general paralysis, but it can be stated that the characteristic histological changes are mainly confined to the cerebral cortex, the Corpus Striatum and the Hypothalamus.

In the floor of the fourth ventricle and to a lesser extent in the walls of the lateral ventricles, a reaction of the subependymal glial cells, with the formation of small granulations, creates the "frosted" appearance of these regions. Frequently much stress is laid upon this finding, which, although common in general paralysis, is by no means specific and is merely part of a general glial reaction in an infective process.

Organic changes of the cerebral vessels are not as common as might be expected, but in about one-fourth of cases of general paralysis an endarteritis of the Heubner variety is found affecting the larger cortical vessels. Concomitant syphilitic meningitis, frequently gummatous, is also met with in a rather smaller proportion of cases, although mild inflammatory changes in the leptomeninges is an almost constant finding. It must be emphasised that in cases with syphilitic meningitis, the underlying cortical process is essentially paretic and not secondary to the meningeal process. It has 


\section{BRITISH JOURNAL OF .VENEREAL DISEASES}

also been noted that cases with a concomitant meningitis frequently run an atypical and often protracted course.

The histological changes in juvenile general paralysis of the insane are essentially of the same nature as in the acquired form of the disease, but tend to be more extensive, and it is sometimes asserted that the degenerative process is comparatively more severe than the inflammatory reaction. The widespread cortical destruction frequently gives rise to internal hydrocephalus of a more pronounced form than is met with in the ordinary acquired type. Further, the glial reaction and iron and fat containing cells are usually more abundant, while evidence such as binucleated cerebellar Purkinge cells indicate the result of the disease upon the further development of the immature organ.

\section{IRON REACTION}

Among the histological findings in general paralysis the demonstration of characteristic deposits of iron pigment is one which merits particular attention, and which is probably less widely recognised, especially in this country, than other pathological changes, such as the perivascular infiltration, which are not nearly so specific in character. Although the presence of iron compounds in the brain had previously been recognised, it was not until r9I3 that Hayashi indicated the significance of the iron-containing cells in general paralysis, and later Spatz developed the technical method associated with his name whereby the demonstration of the iron became a simple and invaluable procedure in the histopathological investigation of the disease. The iron pigment in general paralysis is most characteristic in form and distribution, being found in the adventitial cells of the vessels and to a lesser extent in the hypertrophied Hortega " rod" cells. Using the Spatz method, the iron has the appearance of a dark green pigment, and with the Turnbull method of staining, assumes a vivid blue colour (Fig. 3). In discussing the glial cell changes a reference was made to the Hortega cell reaction occurring in "spontaneous encephalitis" of chickens, and it is most significant that accompanying this outstanding feature of the disease, there are also iron deposits of a nature indistinguishable from those found in general paralysis, 
although as yet spirochætes have not been demonstrated as the causal organism of the avian disease. The distribution of the pigment in general paralysis corresponds roughly to the regions in which the "paralytic process" is usually most marked, that is to say in the cerebral cortex and in the Striatum, and bears no relationship to the normal iron content of the different parts of the brain. Nevertheless, the pigment itself cannot be regarded merely as a by-product of the inflammatory reaction, when it is realised that in the Pons, where perivascular infiltration commonly occurs in general paralysis, a

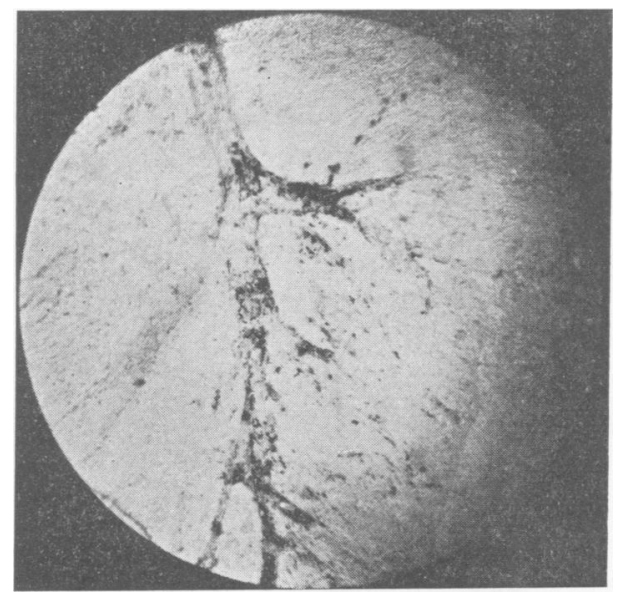

Fig. 3.-Iron pigment around blood vessel.

(Prepared from fresh tissue by Spatz method.)

positive result to the iron reaction has never been described, nor does it appear to exist in such characteristic fashion in other inflammatory cerebral diseases. The deposition of iron pigment in the form of Hæmosiderin in the region of cerebral softenings is of a very different nature, and the only other positive findings have been observed in some cases of Trypanosomiasis. The iron reaction must therefore be considered as one of the most specific, almost pathognomonic, findings in the histological picture of general paralysis, and the simplicity of the test by the Spatz method makes it all the more important as a practical diagnostic criterion. The origin and exact nature of the pigment is still uncertain and perhaps the most likely of the current theories is that it is derived from the circulating blood by direct spirochætal action. 


\section{BRITISH JOURNAL OF VENEREAL DISEASES}

An alternative hypothesis is that there is an increased permeability of the capillaries, allowing the extravasation of blood into the cerebral tissues and consequent absorption of the iron pigment by the adventitial cells and the microglia, which together constitute the reticuloendothelial system of the brain. One further theory which can safely be dismissed is that the pigment is derived from the normal iron content of the nerve cells. Recent work by Tingey ${ }^{1}$ shows that this at least cannot be the only factor at work, as there is an increase of total brain iron in general paralysis. The iron reaction is undoubtedly intimately connected with the active paralytic process, a fact which has been well borne out in the analysis of over a hundred.cases investigated by the author of the present paper. In this series the iron reaction was almost invariably strongly positive in the untreated cases, whereas in the cases which had received adequate malarial therapy the results tended to become progressively weaker and finally became negative according to the length of survival after treatment. Furthermore, the findings in the cerebro-spinal fluid tended to bear a direct relationship to the results of the iron reaction, but even more significant is the fact that in several cases where the fluid was strongly positive but where clinical evidence of general paralysis was absent, the iron reaction rendered a negative result. Further investigation into this series of cases with a view to a closer correlation of the results of the iron reaction with the other pathological, and the serological and clinical findings in each case, is at present in progress, and it is hoped that much useful information will be forthcoming.

\section{Lissauer Type of General Paralysis}

Although there are further pathological findings to be discussed later in connection with the commoner diffuse type of general paralysis, it is convenient at this point to consider the special clinico-pathological syndrome associated with the name of Lissauer. In this condition there are localised areas of cortical atrophy which are clearly visible on macroscopic examination, and which contrast strongly with the more generalised wasting which may also be present. Merritt and Springlova ${ }^{2}$ have made an extensive analysis of thirty-five cases 


\section{GENERAL PARALYSIS OF THE INSANE}

reported in the literature and of eight further cases which they have personally examined, and the following description of the pathological changes in this type of general paralysis is to a certain extent based upon the observations made by these authors.

The exact situation of the localised atrophy varies somewhat in the different cases which have been described, but it usually affects the more posterior parts of the hemispheres, and occurs especially in the Temporal lobes. The atrophic areas are most often, but not exclusively, unilateral. Histological examination of these areas shows that in the cortex the "paralytic " process is not necessarily more severe than in the other better

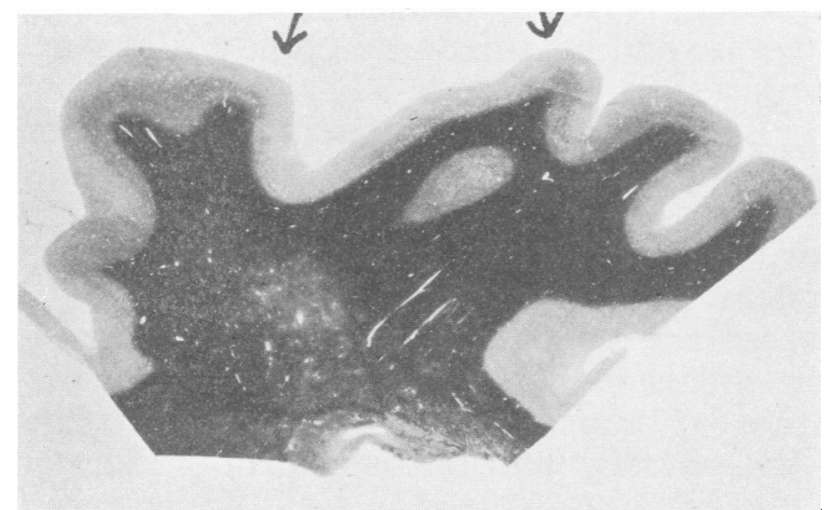

FIG. 4-Demyelinisation in white matter underlying area of cortical atropy in Lissauer type of G.P.I.

preserved regions, but that sometimes there exists an advanced and characteristic form of disintegration known as "spongy state." In this condition there is an extensive destruction of both ganglion cells and ground substance, leaving a reticulated tissue which is largely composed of a coarse network of glial fibres. The outstanding and most consistent finding (in the Lissauer type), however, is situated in the underlying white matter, where extensive demyelinisation and proliferation of glial fibres are observed (Fig. 4). If the process be recent, the breakdown products of the myelin disintegration may also be present to a large extent, with many glial "scavenger" cells loaded with fat, and in places the "sprouting" of newly formed blood vessels indicates 


\section{BRITISH JOURNAL OF VENEREAL DISEASES}

activity of the mesenchymal elements. The demyelinised areas present a characteristic mottled appearance, showing the unevenness of the myelin loss and bearing a superficial resemblance to the "spongy state" of the grey matter. The pathogenetic development of this condition has naturally been the subject of much discussion. Alzheimer proposed that it was an extreme form of the ordinary type of general paralysis, but, as previously indicated, the latter process may not necessarily be more severe in the atrophied areas, nor are the latter unusually rich in spirochætes, which incidentally have only been observed in the white matter, and then in the immediate vicinity of the adjacent cortex, with extreme rarity. Furthermore, status spongiosus is not limited to this condition, and, according to Merritt, etc., may be found in Pick's disease and in Amaurotic Family Idiocy as a more diffuse process in the cortex. It also occurs in Cerebral Arteriosclerosis as numerous circumscribed lesions; in the region of the Putamen in Hepato-lenticular degeneration, and in the spinal cord in Subacute Combined Degeneration. It has also been indicated that the white matter demyelinisation, which forms the essential lesion in the Lissauer type itself, is uneven and sponge-like, with glial fibres replacing the degenerated myelin. The alternative explanation offered by Merritt and Springlova is that the primary fault is vascular in origin, not essentially the result of organic changes in the vessels, for it is rather the exception to find such present, but as the result of a functional spasm or atonia, eventually leading to organic changes in the tissues which are thus rendered anoxæmic. The same authors have also pointed out that the localisation of the atrophied areas most frequently corresponds to the distribution of the middle cerebral artery and especially to its third, fourth and fifth divisions. The clinical manifestations of the syndrome certainly tend to substantiate this ingenious hypothesis, consisting as they are of more or less localised defects, which at first are temporary, occurring in successive attacks, and later tending to become more permanent. Lissauer's Dementia Paralytica should be suspected in every case of general paralysis in which there occurs apoplectiform or unilateral convulsive attacks, especially when they are followed by localising signs such as hemiplegia, aphasia, etc. The author of the present paper has examined a 
most interesting case in which there were multiple atrophies and an old softening in the region of the left Putamen, and with myelin lesions typical of the Lissauer type occurring in relation to some, but not all, of the atrophied areas. This particular case may be considered as an atypical example of the Lissauer type, in that the cortical atrophied areas are multiple, and widespread in their distribution, and that in some instances are evidently unrelated to white matter lesions; but, as Jahnel indicates, one may find transitional forms between the generalised and the clearcut Lissauer type. Jahnel has also noted, as in the present case, the occasional existence of softenings in the Putamen which he considers to be due to syphilitic vascular disease. Lastly, with regard to the author's own case, spongy state was not found in the cortex, but was observed in the posterolateral columns of the spinal cord, as in Subacute Combined Degeneration.

\section{Other Myelin Lesions in General Paralysis}

Lesions of the myelin sheaths are not, however, exclusively confined to the Lissauer type, but occur with surprising frequency in the common type of general paralysis. In the cortex there may be diffuse loss of myelin sheaths involving principally the tangential and supraradiary fibres, or there may be circumscribed areas of demyelinisation (Fig. 5). Spielmeyer has directed attention to the striking resemblance of the latter type of lesion to those found in disseminated sclerosis, and indeed their morphological similarity gave rise to the suggestion that disseminated sclerosis might be due to spirochætal infection. This circumscribed lesion has also been reported frequently in cases of Lissauer's Dementia Paralytica; and this immediately gives opportunity for speculation as to a possible vascular basis for disseminated sclerosis. Similar lesions also occur in Schilder's encephalitis, and also in the type of acute encephalomyelitis which is an occasional sequela of vaccination against small pox. In the latter case the lesions, predominantly in the white matter, seem to have a definite perivascular distribution and in such areas there is also much cellular infiltration, chiefly by microglia. This infiltration is frequently accepted as the natural sequence of an acute 
infective process, and such may be the case, but it must also be borne in mind that it may represent the mobilisation of cells at the site of a lesion of vascular origin which is undergoing active dissolution. Similarly, the mild lymphocytic infiltration of the lesions of disseminated sclerosis need not essentially be evidence of any infective factor in that disease. Nevertheless, our present state of

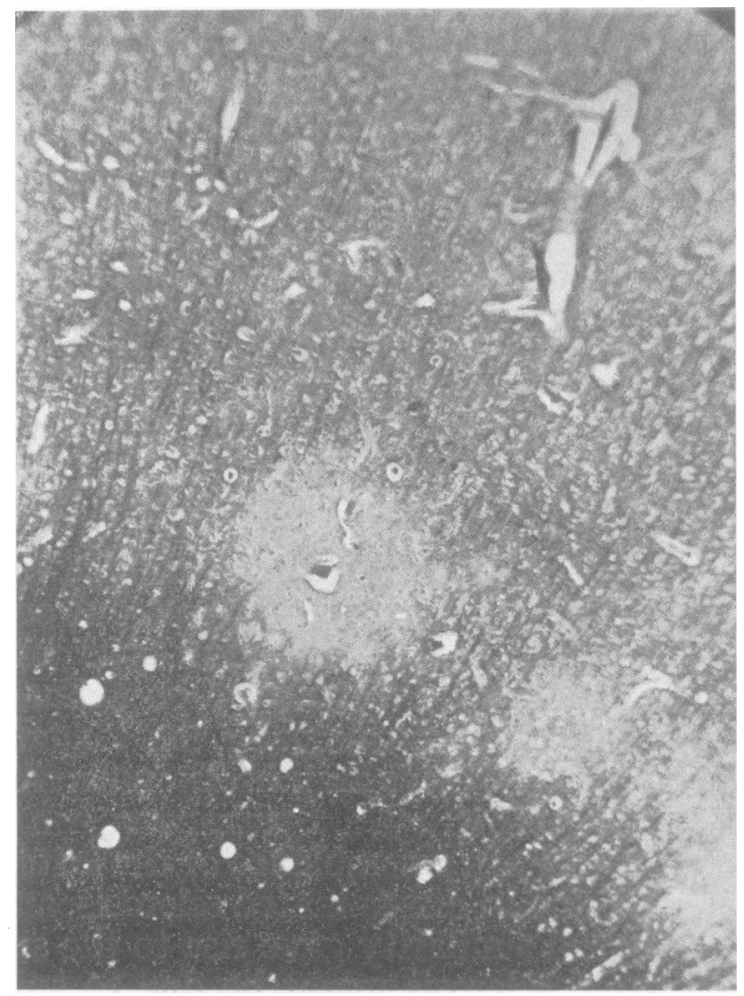

FIG. 5.-Focal demyelinisation in cortex.

knowledge of these peculiar focal myelin disturbances is not sufficiently advanced to make any emphatic declaration as to their origin, and they may yet prove to be the result of local accumulations of toxic substances, rather than the sequence of vascular disturbances. In the white matter of the cerebral hemispheres a further type of demyelinisation may occur in general paralysis. This takes the form of small irregular areas showing a glial scarring, but with preservation of the axis cylinders, features which are again represented in the plaques of 208 


\section{GENERAL PARALYSIS OF THE INSANE}

disseminated sclerosis (Fig. 6). This type of lesion recalls the white matter demyelinisation of the Lissauer type, although on a smaller scale, and further has also been described by Bodechtel ${ }^{3}$ in congenital heart disease. The association of Tabes Dorsalis with general paralysis is a relatively frequent and widely recognised event, and indeed any clinical manifestation occurring in general

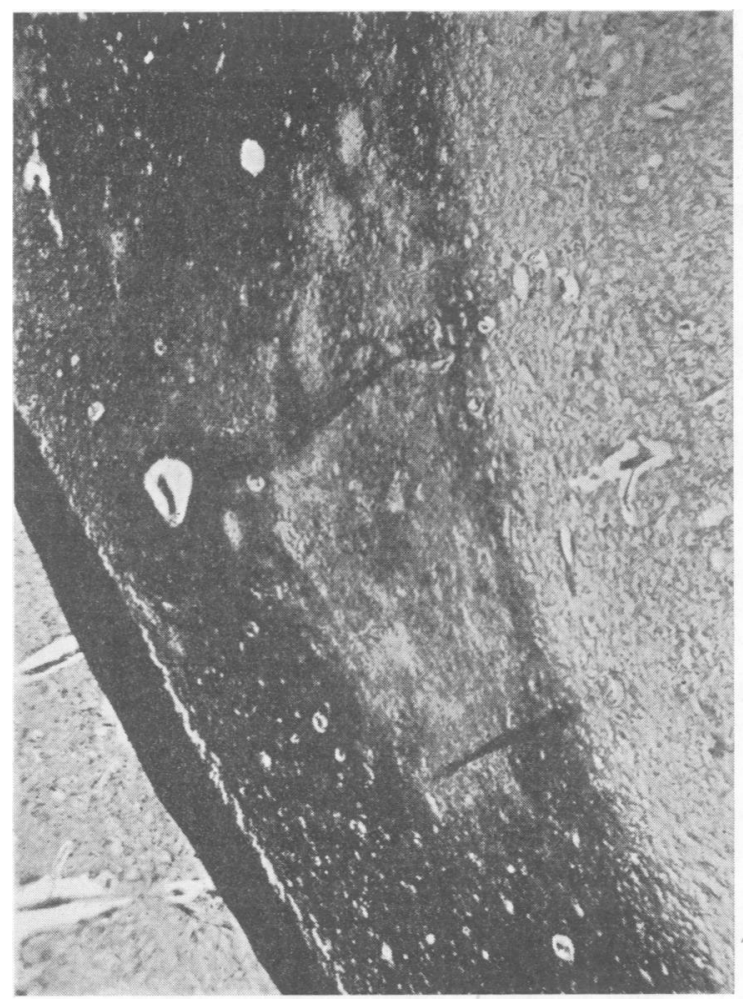

FIG. 6.-Focal demyelinisation in white matter.

paralysis and referable to the spinal cord is apt to lead to an immediate diagnosis of concomitant tabes without any further investigation. Although tabes may be the commonest lesion of the cord in cases of general paralysis, it is well to remember that other forms of degeneration also occur. Thus there may be degeneration of the posterior columns, which is quite distinct from tabes in that the ventral intrinsic fibres, which are invariably spared in tabes, are also involved in the process. Degeneration of the antero-lateral columns may also be found, but so 


\section{BRITISH JOURNAL OF VENEREAL DISEASES}

infrequently that it cannot be presumed to be secondary to cerebral lesions. Combined postero-lateral sclerosis similar to the lesions of Subacute Combined Degeneration have also been described, and attention has already been directed to the status spongiosus of this condition. The morphological features of the wide variety of lesions affecting primarily the myelin sheaths, are of considerable interest per se, yet more important is their etiological relationship, and the recognition of the vascular factor which may be held responsible in some instances at least.

\section{Further Considerations ON THE VAscular Factor}

The myelin lesions which have been described in association with the diffuse form of general paralysis naturally invite further investigation of the possible existence of a vascular factor in other than the Lissauer type. The vulnerability of certain regions of the brain to circulatory disturbances resulting in anoxæmia, gives a possible clue in this direction. Necrosis of the Sommer sector of the Cornu Ammonis is a relatively common finding in general paralysis, but so it is also in epileptic conditions, and the common occurrence of convulsive attacks in general paralysis must be kept in mind when assessing this and other changes attributable to disturbances of oxygenation. Accompanying the sector necrosis, there may be a dense glial sclerosis of the cornu, and the Inferior Olives may also be the seat of gliosis. In the white matter of the cerebral hemispheres there may exist a fine fibre gliosis without demyelinisation characteristic of the case described by Muller. ${ }^{4}$ Similar glioses of the white matter have been described by Meyer ${ }^{5}$ in his recent work on mental defectives, and again suggestive of deficient oxygenation, which in Meyer's opinion may be the factor responsible for the arrested development in these cases of amentia.

Focal "dropping out" of ganglion cells, typical of the type seen in the cortex in general paralysis, has also been produced by experimental carbon monoxide poisoning, and apart from rare instances of " miliary necrosis " (Jahnel) found in relation to localised masses of spirochætes, the occurrence of "dropping out" in general paralysis has not been satisfactorily explained in terms 


\section{GENERAL PARALYSIS OF THE INSANE}

of the infecting organism, and may be yet another instance of the result of anoxæmia.

In a recent paper Merritt et al. ${ }^{6}$ have taken the extreme view, which has not been generally accepted, that in all cases of general paralysis the destruction of ganglion cells is secondary to vascular occlusion of the cortical capillaries as the result of endothelial swelling and proliferation, and not the direct result of spirochætal action. It is true that such vascular changes, and even capillary fibrosis, may be found in general paralysis, but, according to the experience of the present author, in only a very small proportion of cases. The experimental evidence put forward by Merritt, etc., in support of their theory must next be considered. Using dogs as the subjects of their investigation, they isolated a portion of the superior longitudinal sinus by double ligature, and injected into this isolated portion of the vessel a solution of shellac, in order to cause capillary occlusion in that region of the brain drained by the sinus. They claim by this means not only to have produced cortical degeneration identical to that seen in general paralysis, but also to be able to demonstrate a positive iron reaction in the affected area. In criticism of these assertions, it must be said that the more common result of experimental vascular occlusion is the production of narrow bands of sharply demarcated areas of degeneration quite unlike the lesions of general paralysis, and that the iron reaction which these authors have described was probably the result of local exudation of blood from the vessels in which stasis had been produced. Furthermore, the characteristic type of ganglion cell degeneration (ischæmic-homogeneous change) typical of anoxæmic conditions is rarely if ever seen in the cortex affected by the diffuse paralytic process.

\section{Correlation of Clinical and Pathological Findings, ETC.}

It is probably among the ultimate aims of most pathological studies to arrive at some satisfactory correlation between the clinical and pathological aspects of disease, other than the mere isolation of a causal factor.

In the case of general paralysis, any recent advance in our knowledge of the morbid process has been singularly disappointing in this respect. As yet the study of 
the distribution of the pathological changes has thrown little or no light on the different psychotic syndromes, including the hallucinatory psychoses which sometimes develop in treated cases, which are grouped under the heading of general paralysis. The form of the latter may well be determined by the prepsychotic psychological constitution of the individual, rather than by the localisation of demonstrable morbid processes, but it is exceedingly doubtful whether sufficient systematic histological examinations have been made, up to the present time, to exclude definitely the possibility of relating further pathological findings to the form of the psychosis.

The progressiveness of the disease, especially the physical deterioration which may occur when there is every reason to believe that the infective process has been arrested by treatment, may find an explanation in the existence of a superadded vascular factor, or it may be that degeneration continues irrespective of the original inflammatory process, if certain vital structures have been affected, or if a certain total amount of damage has already been reached. These suggestions are of course mere speculation, but the studies of von Braunmühl ${ }^{7}$ have led that author to believe that a second distinct non-inflammatory factor may exist in general paralysis, which he describes as "colloidal disintegration" of the ganglion cells. It is not within the scope of the present paper to discuss in detail the results of treatment, but merely a brief comparative survey of the histological picture at the various stages of the disease, treated and untreated, will be presented. The alterations in the iron reaction have already been discussed, the elimination of the iron corresponding roughly to the changes in the cerebro-spinal fluid, which are criteria of successful antispirochætal action. That a clinical recovery may result, even after the development of obvious psychotic symptoms, is indicative of the stage in the disease process where there is evidence of a reaction to the infective agent, but without destruction of the nerve elements. It is, of course, at this toxic-irritative stage that the maximum response to treatment is obtained, but, as previously indicated, the existence of well-marked psychotic features does not exclude the chance of recovery if adequate therapy is exhibited. Once degenerative changes have set in, it is extremely doubtful whether 


\section{GENERAL PARALYSIS OF THE INSANE}

complete cure is possible, although the removal of the inflammatory element may alleviate the symptoms. In their study of the clinical aspects of general paralysis, Nicol and Hutton ${ }^{8}$ suggested that it might be possible to distinguish between the irritative and the degenerative phenomena, and subsequent histopathological investigations have entirely justified the hypothesis formulated by these authors. The histological picture in cases treated at a later stage of the disease differs from the corresponding untreated case only in the absence or paucity of inflammatory elements. Examination of the brains of patients who have died as the result of some complicating factor during malarial therapy, show that at this stage the inflammatory reaction is notably augmented, suggesting that, whatever the direct action of the pyrexia on the spirochæe, the induction of malaria favours an increased response of the elements which react in the face of an invading organism. General paralysis does not tend to be a self-limiting disease, but, from both clinical and pathological aspects, spontaneous arrest of the process is occasionally encountered and in such instances the histological picture approaches closely the appearance of the successfully treated case, any evidence of the active process being absent or most inconspicuous. Lastly, with regard to the effects of treatment, it can be stated that, whatever the "modus operandi " of the therapy, the original theory held by Jacob that the parenchymatous process was converted into a meningo-vascular condition characterised by the formation of miliary gummata, has since been opposed by the findings of Jahnel and Spielmeyer, and is no longer credited.

\section{ConcLusions}

In conclusion, it must be pointed out that during the past decades the histopathological conception of general paralysis as held by the Nissl-Alzheimer school on the Continent, and by Mott in this country, has been considerably extended. Notable additions to our knowledge of the morphological aspect of the process have been created by the discovery of the iron reaction, by the finer and more selective methods of demonstrating the glial elements, for which we are largely indebted to v.D. 


\section{BRITISH JOURNAL OF VENEREAL DISEASES}

the Spanish school, and by further studies of atypical forms of the process such as the Lissauer type. Histopathology as a scientific method of approach to the problems of disease has become rather unfashionable in this country, mainly because of an entirely false conception that the histological picture of diseases of the nervous system is clear cut and that further development, if possible, will yield nothing of practical significance. It is sufficient to say that our lack of precise knowledge of the fundamental pathogenesis in this direction makes such an idea quite untenable.

In the case of general paralysis there are many problems awaiting our attention. Some of these problems have existed since the original pathological conception of the disease, while others have arisen from the more recent steps in the histological demonstration of the process. Although general paralysis may be one of the best known diseases from the histological aspect, yet even with such an obvious organic basis it may almost be true that the origin of the psychological manifestations, apart from the gross dementia due to cortical destruction in the later stages, is as obscure as in the functional psychoses. The exact circumstances of the invasion of the nervous parenchyma have yet to be elucidated, and it is unknown what factor is responsible for the breach in the " hæmatoencephalic " barrier. Further, we have no explanation to offer for the constant and characteristic distribution of the disease process. A vascular factor has been introduced to explain the development of certain pathological changes such as those encountered in the Lissauer type, but such a factor may only be a connecting link in their pathogenesis and the rôle of the spirochæte in this direction has been neither satisfactorily assessed nor eliminated. Again, with regard to the spirochæe itself, it has not yet been explained why it eludes demonstration in certain cases where there is other undoubted evidence of an active stage of the disease. The exact nature of the iron reaction, which is evidently unknown in other organs affected by syphilis, also merits considerable attention.

This is but an outline of the outstanding problems in the histopathology of general paralysis, and no doubt further questions will arise during their investigation. The remaining consideration is to ascertain the most profitable methods of procedure in the quest of further 


\section{GENERAL PARALYSIS OF THE INSANE}

knowledge in these matters. The possibilities of purely histological research are by no means exhausted, and there is yet much scope in the direction of thorough and systematic examinations of the entire nervous system, and not only of the regions which are known to be commonly affected, paying particular attention to any clues which may be offered in the sphere of correlation of pathological findings with both physical and mental clinical manifestations of the disease. Finally, it may well be ventured that the most promising avenue will eventually prove to be the co-operation of the histologist and the bacteriologist in the field of experimental studies upon the spirochæte. This is probably especially true with regard to the analysis of the localised type of lesion, and the ability to reproduce such findings in the experimental animal would indeed disperse much of the uncertainty in our views upon the pathogenesis of general paralysis of the insane.

The author would like to take this opportunity of expressing his great indebtedness to Dr. W. D. Nicol, Medical Superintendent of Horton Hospital, for his permission to investigate the clinical and pathological material at Horton and to Dr. Nicol and Dr. E. L. Hutton for their help and encouragement throughout the preparation of this paper; to Dr. A. Meyer for his invaluable advice and criticism; to Mrs. A. Meyer for much advice on technical problems and her help in the preparation of micro-photographs and lantern slides; and to Mr. R. H. Treadwell for his willing and skilled assistance in preparing the original specimens.

The author also wishes to acknowledge the assistance he has received from the published works of Professor F. Jahnel, to which repeated references have been made throughout the text of this paper.

\section{REFERENCES}

(I) Tingey, A. H. : “The Iron, Copper and Manganese Content of the Human Brain," Journ. Ment. Sci., I937, 83, 425-460.

(2) Merritt, H. H., and Springlova, M.: “'Lissauer's Dementia Paralytica," Arch. Neur. et Psychiat., I932, 27, 987-1030.

(3) Bodechtel, G. : "Gehirnverändungen bei Herzkrankheiten," Zeitsch.f. d. Neurol. u. Psychiat., I932, 140, 673.

(4) Muller, G. : "Progressive Paralyse mit starber Marksclerose," Zeitsch.f. d. Neur. u. Psychiat., I932, 133, 620. 


\section{BRITISH JOURNAL OF VENEREAL DISEASES}

(5) Meyer, A., and Cook, L. C. : "Diffuse White Matter Gliosis in Mental Defectives," Journ. Ment. Sci., I937, 83, 258-262.

(6) Merritt, H. H., Putnam, T. J., and Campbell, A. C. : " Pathogenesis of the Cortical Atrophy Observed in Dementia Paralytica," Arch. Neur. et Psychiat., 1937, 37, 75-90.

(7) Von BRaunmüHL, A.: " UUber Versuche einer kolloidchemischen Pathologie zur Klärung grundsätzlicher Fragen einer Paralyseanatomie dargestellt am Beispiel der Lissauerschen Paralyse," Zeitsch. $f$. $d$. Neur. u. Psychiat., I933, 148, I-27.

(8) Nicol, W. D., and Hutron, E. L. : " Some Clinical Aspects of General Paralysis," Journ. Ment. Sci., I935, 81, 804-821. 